\title{
COMMENTARY
}

\section{Biological effects of cancer-secreted factors on human mesenchymal stem cells}

Paula YP Lam ${ }^{1,2,3}$

See related research by Al-Toub et al., http://stemcellres.com/content/4/5/114

\begin{abstract}
Mesenchymal stem cells or mesenchymal stromal cells (MSCs) have been considered as a carrier of therapeutic gene because of their inherent ability to migrate to the tumors, and yet there are controversial reports suggesting the tumor-promoting and tumor-inhibiting effects of MSCs. Al-Toub and colleagues provide further insights into the cellular interactions between MSCs and tumors and demonstrate that conditioned media derived from different cancer cells could influence MSC phenotype and gene expression. These changes in MSCs may be modulated by the tumor-derived interleukin-1 beta (IL-1 $\beta$ ) and transforming growth factor-beta (TGF- $\beta$ ) signaling.
\end{abstract}

A report from Al-Toub and colleagues [1] in the previous issue of Stem Cell Research \& Therapy provides further insights into how cancer influences the biological properties of human mesenchymal stem cells. Mesenchymal stem cells or mesenchymal stromal cells (MSCs) were first described by Friedenstein and colleagues [2] as plasticadherent, non-hematopoietic stromal cells (approximately $0.0001 \%$ to $0.001 \%$ of the nucleated cells) in the bone marrow and later were identified in many tissue types. The multipotent potential of MSCs makes them an excellent cell source for regenerative medicine. MSCs are poorly immunogenic because of low expressions of major histocompatibility complex (MHC) class I and absence of MHC class II [3]. Thus, MSCs have been used in clinical trials for the treatment of many diseases, including cartilage and bone injury [4] and inflammation-associated disorders [5].

\footnotetext{
Correspondence: cmrlyp@nccs.com.sg

${ }^{1}$ Laboratory of Cancer Gene Therapy, Cellular and Molecular Research

Division, Humphrey Oei Institute of Cancer Research, National Cancer Centre,

11, Hospital Drive, Singapore 169610, Singapore

2Department of Physiology, Yong Loo Lin School of Medicine, National

University of Singapore, 21 Lower Kent Road, Singapore 119077, Singapore

Full list of author information is available at the end of the article
}

MSCs possess an innate tropism for injured tissues and tumor cells [6]. This attraction is thought to be mediated through a paracrine signaling loop between the chemoattractants from the tumor microenvironment and the expression of the corresponding receptors in MSCs or vice versa. The ability of these MSCs to track pathological lesions and microscopic tumors has posed a significant clinical potential as these cells may potentially be employed for tracking or targeting metastasis and tumors which are inaccessible for resection. As a consequence, many research strategies have been developed to modify MSCs as a cargo of therapeutic genes for cancer gene therapy.

On the flip side of the coin, the impact of MSCs on the development and spread of tumors is poorly understood. MSCs may interact with tumor cells directly or indirectly through the secretion of paracrine factors. MSCs were first demonstrated to enhance the metastatic potency of breast cancer cells, MDA-MB-231 cells, via de novo secretion of the chemokine CCL5 (also known as RANTES, or regulated on activation, normal $\mathrm{T}$ cell expressed and secreted) [7]. Mishra and colleagues [8] have independently shown that MSCs exposed to conditioned media from the same MDA-MB-231 breast tumor cells could differentiate into carcinoma-associated fibroblasts and become part of the tumor microenvironment. MSC-derived carcinomaassociated fibroblasts are thought to regulate epithelialmesenchymal transition (EMT) and tumor-initiating stem cells in tumor [9]. Recently, McGrail and colleagues [10] demonstrated that tumor-secreted soluble factors could promote MSC mobility by inducing cytoskeletal changes through activating the RhoA pathway. However, the precise effect of MSCs from tumor-derived conditioned media (TCM) is unclear. It is also unknown whether all cancer cells exert similar effects on MSCs. In this study, $\mathrm{Al}$-Toub and colleagues demonstrate that MSC responses to TCM are cell line-dependent [1]. Thus, MSCs could either acquire a spindle shape or retain their native cell shape, depending on the types of TCM the MSCs have been exposed to. Gene expression analysis revealed that 
tumor-derived interleukin-1 beta (IL-1 $\beta$ ) is one of the factors responsible for the differential morphological changes. Treatment of MSCs with recombinant IL-1 $\beta$ mimicked the effects of TCM on MSCs via the focal adhesion kinase and, to a lesser extent, mitogen-activated protein kinase pathways. These biological effects may be counteracted through pharmacological inhibition of the transforming growth factor-beta (TGF- $\beta$ ) signaling in MSCs in the presence of TCM. These findings provide support that the transition of MSCs to myofibroblast is modulated by multiple signaling ligands that interact directly or indirectly via the TGF- $\beta$ signaling cascade.

Further investigations are required to understand the differential effect of TCM on MSCs. It is interesting that $\mathrm{IL}-1 \beta$ is one of the mediators of the pro-inflammatory phenotype observed in MSCs exposed to TCM. Carrero and colleagues [11] have demonstrated that IL-1 $\beta$ increases migration and adhesion of MSCs and promotes leukocyte chemotaxis through soluble factors secreted by MSCs. The anti-tumor effect of MSCs on glioma has also been shown to inhibit IL-1 $\beta$ signaling which significantly impaired tumor angiogenesis via modulation of cathepsin B expression [12]. Alternatively, tumor-derived IL-1 $\beta$ could promote MSCs to undergo EMT by modulating the TGF- $\beta$ signaling cascade, thus increasing the self-renewal capability of tumor cells. The cooperation of IL- $1 \beta$ and TGF- $\beta$ has been shown to promote the neurosphere formation in glioma [13].

However, the tumor microenvironment is complex, consisting of different stromal cells, including tumor cells, tumor-associated fibroblasts, endothelial cells, pericytes, adipocytes, and immune cells [14]. The complexity of the system is further increased by the environmental signals, the difference of MSC source and donor variation, and the intra-population heterogeneity and species difference since most of the preclinical tumorigenesis studies are performed by using human MSCs in immunocompromised rodents. Hence, it is of great importance to advance our understanding of MSC biology before implementation in clinical therapy.

\begin{abstract}
Abbreviations
EMT: Epithelial-mesenchymal transition; IL-1ß: Interleukin-1 beta; MHC: Major histocompatibility complex; MSC: Mesenchymal stem cell; TCM: Tumor-derived conditioned media; TGF- $\beta$ : Transforming growth factor-beta.
\end{abstract}

\section{Competing interests}

The author declares that she has no competing interests.

\section{Acknowledgments}

PYPL is supported by the National Medical Research Council, Singapore (NMRC/1201/2009 and NMRC/CG/007/2013).

\section{Author details}

${ }^{1}$ Laboratory of Cancer Gene Therapy, Cellular and Molecular Research

Division, Humphrey Oei Institute of Cancer Research, National Cancer Centre, 11, Hospital Drive, Singapore 169610, Singapore. ${ }^{2}$ Department of Physiology, Yong Loo Lin School of Medicine, National University of Singapore, 21 Lower Kent Road, Singapore 119077, Singapore. ${ }^{3}$ Duke-NUS Graduate Medical School, 8 College Road, Singapore 169857, Singapore.
Published: 15 Nov 2013

\section{References}

1. Al-Toub M, Almusa A, Almajed M, Al-Nbaheen M, Kassem M, Aldahmas A, Alajez NM: Pleiotrophic effects of cancer cells' secreted factors on human stromal (mesenchymal) stem cells. Stem Cell Res Ther 2013, 4:114.

2. Friedenstein AJ, Chailakhjan RK, Lalykina KS: The development of fibroblast colonies in monolayer cultures of guinea-pig bone marrow and spleen cells. Cell Tissue Kinet 1970, 3:393-403.

3. Barry FP, Murphy JM, English K, Mahon BP: Immunogenicity of adult mesenchymal stem cells: lessons from the fetal allograft. Stem Cells Dev 2005, 14:252-265.

4. Qi Y, Feng G, Yan W: Mesenchymal stem cell-based treatment for cartilage defects in osteoarthritis. Mol Biol Rep 2012, 39:5683-5689.

5. Uccelli A, Prockop DJ: Why should mesenchymal stem cells (MSCs) cure autoimmune diseases? Curr Opin Immunol 2010, 22:768-774.

6. Chan JK, Lam PY: Human mesenchymal stem cells and their paracrine factors for the treatment of brain tumors. Cancer Gene Ther 2013, 20:539-543.

7. Karnoub AE, Dash AB, Vo AP, Sullivan A, Brooks MW, Bell GW, Richardson AL, Polyak K, Tubo R, Weinberg RA: Mesenchymal stem cells within tumour stroma promote breast cancer metastasis. Nature 2007, 449:557-563.

8. Mishra PJ, Mishra PJ, Humeniuk R, Medina DJ, Alexe G, Mesirov JP, Ganesan S, Glod JW, Banerjee D: Carcinoma-associated fibroblast-like differentiation of human mesenchymal stem cells. Cancer Res 2008, 68:4331-4339.

9. Polyak K, Weinberg RA: Transitions between epithelial and mesenchymal states: acquisition of malignant and stem cell traits. Nat Rev Cancer 2009, 9:265-273.

10. McGrail DJ, Ghosh D, Quach ND, Dawson MR: Differential mechanical response of mesenchymal stem cells and fibroblasts to tumor-secreted soluble factors. PLoS One 2012, 7:e33248.

11. Carrero R, Cerrada I, Lledó E, Dopazo J, García-García F, Rubio MP, Trigueros C, Dorronsoro A, Ruiz-Sauri A, Montero JA, Sepúlveda P: IL1 $\beta$ induces mesenchymal stem cells migration and leucocyte chemotaxis through NF-KB. Stem Cell Rev 2012, 8:905-916.

12. Ho IA, Toh HC, Ng WH, Teo YL, Guo CM, Hui KM, Lam PY: Human bone marrow-derived mesenchymal stem cells suppress human glioma growth through inhibition of angiogenesis. Stem Cells 2013, 31:146-155.

13. Wang L, Liu Z, Balivada S, Shrestha T, Bossmann S, Pyle M, Pappan L, Shi J, Troyer D: Interleukin-1 $\beta$ and transforming growth factor- $\beta$ cooperate to induce neurosphere formation and increase tumorigenicity of adherent LN-229 glioma cells. Stem Cell Res Ther 2012, 3:5.

14. Albini A, Sporn MB: The tumour microenvironment as a target for chemoprevention. Nat Rev Cancer 2007, 7:139-147.

\subsection{6/scrt349}

Cite this article as: Lam: Biological effects of cancer-secreted factors on human mesenchymal stem cells. Stem Cell Research \& Therapy 2013, 4:138 